\title{
An investigation of sales managers' aggressiveness in B2B sales leadership: The sequential media- tion model of emotional exhaustion and adaptive selling
}

\author{
Bilal Ahmad $^{a^{*}, \text { Muhammad Imad ud Din Akbar }^{b}, \text { Mirza Huzaifa Asif }^{\mathrm{a}} \text { and Naila Nureen }}{ }^{\mathrm{a}}$
}

${ }^{a}$ School of Economics and Management, North China Electric Power University, China

${ }^{b}$ Department of Management Sciences, National University of Modern Languages, Pakistan

\section{H R O N I C L E}

\begin{tabular}{l}
\hline Article history: \\
Received: December 5, 2020 \\
Received in revised format: \\
April 102021 \\
Accepted: April 10, 2021 \\
Available online: \\
April 10, 2021 \\
\hline Keywords: \\
Sales Managers' Aggressiveness \\
Ethical Sales Leadership \\
Emotional Exhaustion \\
Manager Decisiveness \\
Salesperson performance \\
B2B Selling
\end{tabular}

\section{A B S T R A C T}

\begin{abstract}
The aim of this research is to investigate the influence of sales managers' aggressiveness on ethical sales leadership and salesperson performance in B2B context, taking into consideration the sequential mediation of emotional labor and adaptive selling behavior. Sales managers spend most of their time in solving salesforce-related issues, while empirical studies have largely neglected such factors that can have negative consequences on salesforce-related tasks. In order to overcome this gap in the literature, we draw from conservation of resources (COR) theory to introduce and establish an advanced theoretical paradigm. The authors tested the model through 336 responses from B2B salesperson-manager dyads. The findings of the study reveal that sales managers' aggressiveness has a negative association with ethical sales leadership. Also, sales managers' aggressiveness is positively related to emotional exhaustion and negatively related to salesperson performance. Consequently, we found significant serial mediation of ethical sales leadership and adaptive selling behavior between the relationship of sales managers' aggressiveness and salesperson performance. In last, manager decisiveness is playing as a significant moderator in the study. Theoretical contributions and practical implications are also discussed.
\end{abstract}

(C) 2021 by the authors; licensee Growing Science, Canada

\section{Introduction}

Over the past decade, ethical leadership in the B2B sales context has gained increased academic and managerial attention. Prior literature has suggested that displays of ethical sales leadership have several favorable effects on salespeople (Ingram et al., 2013; Wu, 2017). The sales profession is exceptional in light of how often salespeople face rejections and disappointments (Dixon \& Schertzer, 2005). The challenges encountered in the sales position will build a training environment for emotional exhaustion (Jaramillo et al., 2011; Lewin \& Sager, 2008), and unethical sales practices (Li \& Murphy, 2012). While much is documented about the benefits of ethical leadership for followers, the ramifications of ethical leadership in the B2B sales context have received less attention. In sales organizations, ethical leader behaviors are something that needs to be improved above and beyond the fundamental task-focused. In this regard, growing numbers of studies have been reported for sales managers' negative behavior toward the salespeople (Valentine et al., 2015), such as manager aggressiveness which is described by Geddes and Baron (1997) as "subordinates' perceptions of the extent to which managers engage in the sustained display of hostile verbal and non-verbal behaviors, excluding physical contact." In fact, salespeople with aggressive behavior are expected to have a higher amount of unpleasant and traumatic interactions. Additionally, subjective perceptions are focused on the existence or absence of aggressive management, although one salesperson may find a manager aggressive, an-

\footnotetext{
* Corresponding author. Tel. 1: +923227507720

E-mail address: bilalahmad12382@yahoo.com (B. Ahmad) 
other salesperson may feel differently under the same supervisor. The previous workplace aggression literature further indicates that aggressive resources spent by sales managers in the problem-solving situation might have a key impact on salesperson-manager relationship quality (Lee \& Cadogan, 2009; Lee et al., 2018).

The COR theory has been developed as an important framework for further analyzing ethical behaviors (Hobfoll, 1989). Individuals with a lower level of emotional resources are more likely to "spontaneously mislead" (i.e., engage in unethical behaviors) than individuals whose emotional resources are stable (Gino et al., 2011). Salespeople can view ethical leadership as managerial determinations to foster a favorable working environment through motivation and valuable feedback (Wu, 2017). This positive work climate helps salespeople to express themselves, take guidance and obtain useful insights, thus reducing emotional exhaustion and enhancing the adaptation of different selling techniques. As a result, such leadership support can reduce the negative effects of emotional exhaustion on salesperson performance. This study contributes to theory as well as practice by offering indication of the sequential existence of sales managers' aggressiveness on salespersons' outcomes. From a theoretical perspective, we contribute to the leadership and sales management literature in several ways. First, we contribute to the area of sales management - problem resolution by investigating sales managers' negative behaviors under ethical leadership settings. Our structural model contains sales managers' aggressiveness as a potential predictor of ethical sales leadership. Second, the research contributes to the business to business literature, as we have studied the current model in the B2B sales context. Further, limited studies on ethical sales leadership have been conducted by sales scholars. The study also contributes to the prior literature by exploring ethical sales leadership, emotional exhaustion, and adaptive selling behavior as potential serial mediators of sales managers' aggressiveness and salesperson performance relationship. In managerial terms, we suggest that successful managers should be more issue-focused and do not let aggression and bullying into their managerial style. Our findings also indicate that a lower level of aggressiveness could relate with a minor level of emotional exhaustion and a greater level of ethical sales leadership and performance.

\section{Literature review and hypotheses development}

\subsection{Sales managers' aggressiveness and ethical sales leadership}

There has been a rise of scholarly attention in the topic of workplace aggression over the last two decades. Research on negative management behaviors mainly focused on workplace aggression (Aquino \& Thau, 2009; Sprung et al., 2012). Such practice has no benefit in the workplace environment, indicating that aggression is coupled with several negative effects, including weak employees' performance. Unethical conduct can be enhanced by encouraging behavior that breaches ethical standards, by putting too much on managerial aggression and corporate performance at all costs and competition (Sims \& Brinkmann, 2002). Concentrating on aggression rather than criticism, Aquino et al. (2004) found that in terms of relationship deviation, leader interpersonal fairness and aggressiveness operate in a different way to influence follower's different status positions (i.e., race, gender, and job tenure). Ethical sales leaders could be perceived as having a higher sense of achievement to senior managerial positions, particularly in environments where performance pressure is high (Schwepker \& Ingram, 2016). Previous literature have also revealed that situations under high pressure are associated with unethical behavior (Zheng et al., 2015). Another study by Brown \& Treviño (2006a) has found that ethical leadership style is negatively associated with outcomes such as manager's aggressive behavior. Although, ethical leadership performs at higher levels of moral reasoning (Brown \& Mitchell, 2010), and transforms their followers into moral leaders. We have concluded that ethical sales leadership and managers' aggressiveness operate very much in the same way but opposite directions. However, the association between ethical sales leadership and managers' aggressiveness could be too much complicated than just "equal but opposite". Thus, we intend the following hypothesis.

\section{$\mathbf{H}_{1}$ : Sales managers' aggressiveness is negatively related to ethical sales leadership.}

\subsection{Ethical sales leadership and emotional exhaustion}

A constant feature of the sales profession is to cope with a high level of pressure, hardships, and failures (Dixon \& Schertzer, 2005). These diverse requirements and obstacles make emotional exhaustion a nearly unavoidable challenge for salespeople, which tends to happen in the context of the sales profession (Jaramillo et al., 2011). According to Wu (2017), ethical sales leadership can encourage salespeople positive attitudes, promote a greater level of engagement and dignity within the company, and influence the way salespeople visualize the context of ethical work; such positive behaviors can minimize salespeople's emotional exhaustion in a dynamic sales environment. Viewing ethical sales leadership as an important source for salespeople, we draw on conservation of resource (COR) theory (Hobfoll, 1989) to suggest that ethical sales leadership reduces the emotional exhaustion of sales employees. The perspective of resource loss, a threat to resources, and failure to acquire new resources can contribute to stress (Hobfoll, 1989). The context of emotional exhaustion includes both the circumstance and the individual (Halbesleben, 2006; Wang et al., 2010). Ethical sales leadership is one of the aspects of the situation (Zheng et al., 2015). The impact of a greater level of ethical sales leadership on salespeople involves: (1) greater satisfaction and commitment (2) greater tasks and performances (3) fewer dishonesty and immoral conduct (4) greater well-being. Thus, we propose the following hypothesis. 
$\mathbf{H}_{2}$ : Ethical sales leadership is negatively related to salespersons' emotional exhaustion.

\subsection{Ethical sales leadership and adaptive selling behavior}

Adaptive selling is described as a variation in a salesperson's behavior when selling a product to a customer (Spiro \& Weitz, 1990). Customers react favorably to salespeople who use a wide range of adaptive selling techniques (Itani et al., 2017). According to previous research, salespeople are more likely to understand consumer interest and various selling situations so they can quickly adjust their presenting skills (Limbu et al., 2016). As previously mentioned, ethical leaders represent personal resources (e.g., justice, honesty, and empathy for others) as well as resources for social support (e.g., power networking, ethical value enhancement, and moral advice) (Kalshoven et al., 2011). When salespeople encounter trust in their relationship building with their managers, they are more likely to take positive customer-oriented approaches (Busch \& Bush, 1978). Ethical sales leaders can encourage salespeople to improve the ability to adjust selling approaches for quality services by developing loyalty and cooperative behavior among sales employees. Salespeople may proactively gather more information from and about stakeholders, as well as feedback from supervisors and peers, to make the best improvements in sales strategies. Salespeople with adaptive selling abilities are not only innovative in their sales approaches (Singh \& Das, 2013), but they are much more likely to go beyond and above the minimum required thresholds in customer service activities. Therefore, we suggest from the above argument that the more sales managers will display their ethical leadership behavior, the more salespeople will engage in different selling approaches for achieving customer-oriented outcomes. Thus, suggesting the following hypothesis.

\section{H3: Ethical sales leadership is positively related to adaptive selling behavior.}

\subsection{Emotional exhaustion and salesperson performance}

Emotional exhaustion (EE) is the sentiment of being emotionally overstretched and depressed by one's work. Sales managers are cautious with emotional exhaustion because it affects both salesperson performance and turnover (Lewin \& Sager, 2009). The association between both EE and the success of salespeople through the COR paradigm seems to be the notion that inspiration is the allocation of resources. In the theory of (Hobfoll, 1989), motivation acts as an energy resource, in fact COR theory explicitly identifies balance of work and motivation as part of a list of COR resources to get things done. To relate the concept of inspiration as a resource, the linkage among EE and salesperson performance needs further research into the concept of resource investment (Hobfoll, 1989). As a result of lack of resources or the possibility of loss, salespeople prefer to take necessary actions to protect their resources. In order to protect their resources, salespeople put little energy into their task (low motivation), which leads to poor work outcomes (Lewin \& Sager, 2009). Toward this stage, most of the studies on the nexus among EE and salesperson performance have been neglected to investigate in the B2B sales context. It is expected that $\mathrm{EE}$ will lead to lower performance as salespeople tend to feel less able to perform tasks at work and they become more depressed (Lam et al., 2017). Also, because the desire for achievement is associated with the ability to complete the task at work, so when struggling for achievement decreased, one might assume that salesperson in-role performance would also drop (Nguyen et al., 2019). Therefore, we proposed the following hypothesis.

\section{H4: Emotional exhaustion is negatively related to salesperson performance.}

\subsection{Adaptive selling behavior and salesperson performance}

Adaptive selling improves the salesperson's ability to develop good connections with consumers and become more successful in selling by creating new approaches for each customer, which improves the salesperson's output. Previous literature has shown a favorable association between adaptive selling behavior and salesperson performance (Jaramillo et al., 2007). Meanwhile, self-scores salespeople, manager scores, and all relevant measures of success are used to determine outcomes. According to Itani et al. (2017), adaptive selling behavior is a salesperson's willingness to effectively strengthen the salesperson's capability to establish a successful collaboration with customers, which inevitably influences sales performance. It is suggested by Singh and Das (2013), many personal characteristics of salespeople might explain the effectiveness of adaptive selling behavior exhibited by a salesperson. To successfully use adaptive selling, it is critical to have strong information acquisition and processing skills (Weitz et al., 1986). In addition, adaptive selling behavior asserts that a salesperson's ability to adapt their various communication styles to particular customers in a range of selling situations must be linked to success. The salesperson who is more adaptable is more likely to produce personalized presentations, which influences the salesperson's performance (Limbu et al., 2016; Yoon et al., 2020). Therefore, we suggest from the above argument that the more salespeople will engage in adaptive selling behavior, the more chances would be to improve in salesperson performance.

\section{H5: Adaptive selling behavior is positively related to salesperson performance.}

\subsection{Sales managers' aggressiveness, and salesperson performance}

Due to the adverse impact of managerial aggression on salespeople and corporations, it is necessary to analyze the process by which aggression causes distress and the factors that influence the relationship of managers' aggressiveness and salespeople 
outcomes (Sprung et al., 2012). Previous research has concentrated mainly on the offensive leader's identity; it has been known as manager aggressiveness (Micevski et al., 2017). Meanwhile, the managers' negative supervision style with their followers is not yet clearly studied in the B2B sales context. Therefore, we are intended to address this crucial gap in existing research.We draw on the conservation of resources (COR) theory as a key descriptive mechanism for predicting the link between sales managers' aggressiveness and salesperson performance. COR theory (Hobfoll, 1989) indicates that mental stress in four specific situations is expected to have adverse effects on overall performance:1) If there is a higher possibility of lack of resources, 2) Unless there has been a genuine loss of resources, 3) When the employees understand that perhaps the burden of work lacks resources, and 4) when a resource investment could not contribute to the projected returns (Hobfoll, 2001). We propose that these four conditions may generate aggressiveness and thus contribute to a negative impact on salesperson performance. Under high aggressive management, team members are less likely to consciously transfer and express their knowledge and experiences in sales teams, and they hesitate to incorporate their ideas into anything new and useful (Geddes \& Baron, 1997), which negatively impact objective sales performance. According to Sprung et al. (2012), to reduce the negative effects of unequal treatment, salespeople respond to managers' aggressiveness by reducing the level of their job performance. Therefore, we intended the following hypothesis.

H6: Sales managers' aggressiveness is negatively related to salesperson performance.

\subsection{Manager decisiveness as a moderator}

Sales managers are continuously confronted with conditions asking for their decisions that are important for the company and have a great impact on the salesperson's performance and their professional careers. Decisiveness is an individual characteristic in which managers are confident and relaxed in taking decisions while confronted with the dilemma that resolves psychological difficulties (Germeijs et al., 2006). Decisive managers are seen as being straightforward about their objectives and about taking measures to action (Barrick \& Zimmerman, 2005). In contrast, indecisive managers are those who avoid making decisions, ignore judgments from anyone else, and sometimes worry and regret about past decisions (Germeijs et al., 2006). However, salespeople are willing to establish constructive attitudes toward the managers and the organization. When the manager is decisive, he/she does not cancel the commitments and feels less insecure when enforcements are made for regulating procedures (Mulki et al., 2012). Managers contribute in persuading the emotional exhaustion of employees (Mulki et al., 2006). The decisions of managers are of greatest priority to salespeople because they affect their performance, incentive schemes, employment, regional allocations, and promotions (Do et al., 2020) (Schwepker, 2019). Decisive sales managers, with limited experience, make prompt decisions, such as approving a price discount to close an important sale. Although, emotional stress in various professions gives a good understanding of this problem as a whole and minimizes its effect on performance, career, and job engagement (Schwepker \& Ingram, 2016). In such conditions, salespeople will develop a positive perception of their managers and should display less emotional exhaustion, and will experience better job performance. In reference to this discussion, it can be reported that the influence of EE on salesperson performance will reduce when salespeople believe their manager is decisive. Therefore, we proposed the following hypothesis.

\section{H7: The relationship between emotional exhaustion and salesperson performance is moderated by managers' decisiveness such that the effect of emotional exhaustion on salesperson performance will be lesser; when salespeople perceive that their manager is decisive.}

\subsection{The serial mediation model of emotional exhaustion and adaptive selling behavior}

According to Lewin and Sager (2009), emotionally exhausted salespeople have exploited their stress control for avoidance and withdrawal. The most harmful of these salespeople's withdrawal-related emotional exhaustion is associated with low job satisfaction and reduced outcome performance. It has also drawn extensive attention from researchers and practitioners due to its relation to lower salesperson performance (Halbesleben \& Bowler, 2007). Although in business-to-business sales professionals, previous pieces of evidence have revealed the relationship among ethical leadership and employee outcomes such as employee performance and job satisfaction (Schwepker, 2015; Walumbwa et al., 2011). According to Zheng et al. (2015), there has been growing empirical interest by scholars on ethics and describes a psychological mechanism in which ethical sales leadership has both direct and indirect influence on EE. Although, ethical sales leadership and aggressive managers both require a consistent practice of actions, as ethical leadership involves normatively acceptable behavior, while aggressive management requires normatively misbehavior.

On the other hand, the findings also propose that the positive indirect connections between sales managers' aggressiveness and salesperson performance exist through the serial mediation of ethical sales leadership and adaptive selling behavior. Although, salespeople are more likely to take proactive customer-oriented approaches when they experience trust in their friendly relationships with sales managers (Busch \& Bush, 1978). By improving salespersons' loyalty and interpersonal trust, ethical leaders can encourage their team to proactively develop the capacity to adapt different sales techniques in servicing customers (Singh \& Das, 2013). In particular, ethical leadership behavior can reduce aggressive management at work, which turns into the lower level of emotional exhaustion, and ultimately encourage salesperson performance. Thus, we intended the following hypothesis. 
$\mathbf{H}_{\mathbf{8}}$ : Sales managers' aggressiveness is negatively related to salesperson performance through the mediating role of ethical sales leadership and emotional exhaustion

$\mathbf{H}_{\mathbf{8}}$ : Sales managers' aggressiveness is positively related to salesperson performance through the mediating role of ethical sales leadership and adaptive selling behavior

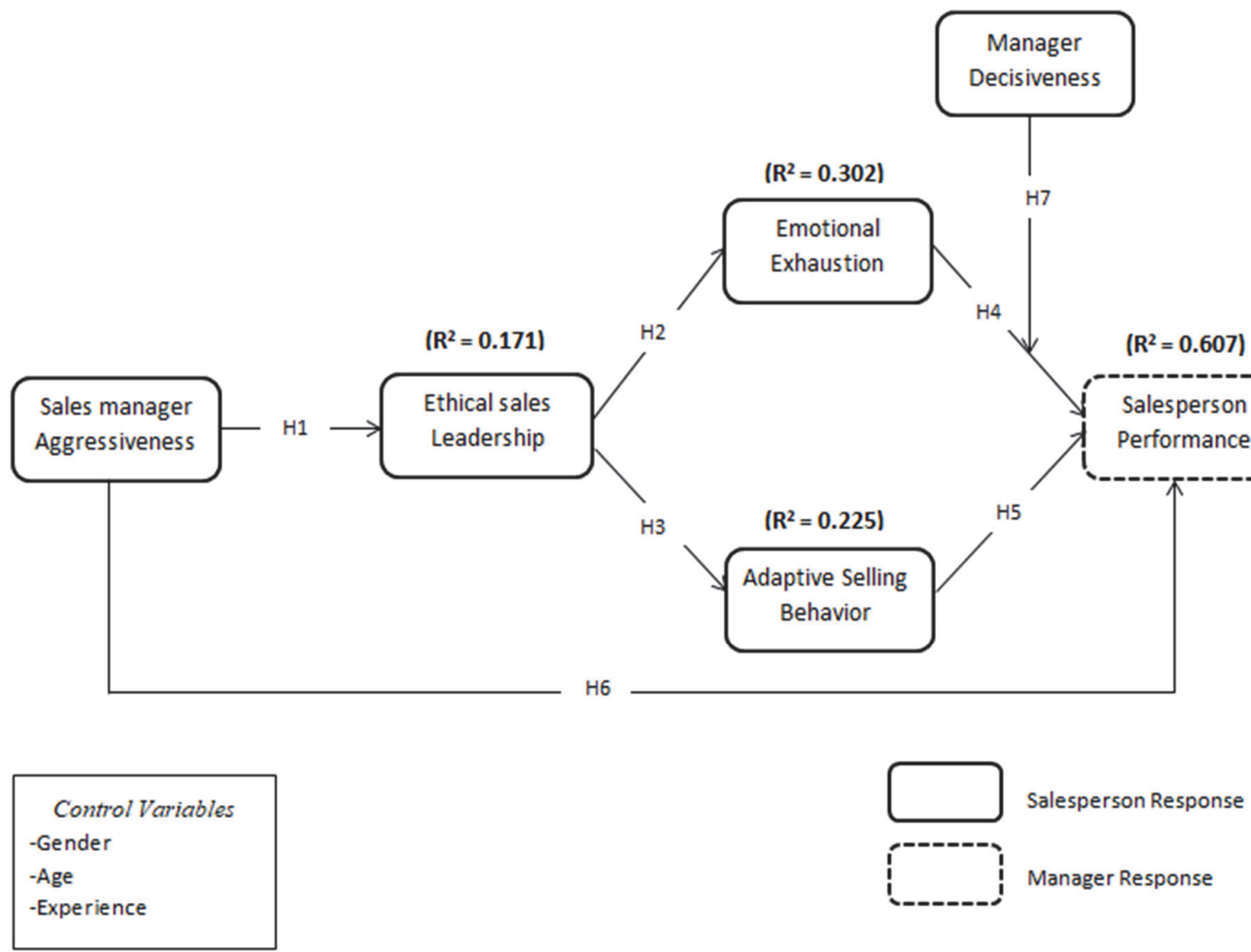

Fig. 1. Conceptual Framework

\section{Method}

\subsection{Sample and data collection}

The study is descriptive and cross-sectional in nature. In order to confirm the hypotheses, we employed a dyadic approach that includes salesperson-manager surveys under the B2B sales setting in Pakistan. Participants were allowed to work in sales, but not in any specific sector. Therefore, a wide number of sectors were considered for the survey, particularly manufacturing, services, technology, and retail. The studied sales organizations had a hierarchical structure in which a number of salespeople worked under the supervision of sales managers. To measure the salesperson's performance, we requested the sales managers to evaluate individual performance separately of each salesperson just to avoid the common method biased. Out of the 89 contacted companies, 62 companies decided to participate in the study. After the agreement of enterprises collaboration on average one manager and from one to four salespeople randomly selected in each organization with the help of the human resource and sales departments, when appropriate. We distributed survey questionnaires to 388 salespeople and their 97 sales managers. An online survey link was emailed to the sales managers and asked to send the link to each salesperson. After the survey completion, the total sample size resulted in 353 matched salespeople-manager questionnaires. However, we omitted 17 questionnaires due to incomplete and unengaged responses. The final sample of $336(86.59 \%)$ questionnaires was used for analysis purposes. Among the salespeople, $81.5 \%$ were male, the average age was 30.4 years and the average sales experience was 9.2 years. Among the sales managers, $91.8 \%$ were male and the average age was 42.6 years. A method by Kock (2015) was adopted to evaluate the common method variance (CMV). According to this method, the study shows the factor level VIF value less than the acceptable 3.3 thresholds, taking into account that the model is free from common method variance. Therefore, CMV is not an issue in this study. 
Table 1

Descriptive statistics, correlation and, discriminant validity.

\begin{tabular}{|c|c|c|c|c|c|c|c|}
\hline S. No & Variable & 1 & 2 & 3 & 4 & 5 & 6 \\
\hline 1 & Emotional Exhaustion & 0.736 & & & & & \\
\hline 2 & Ethical Sales Leadership & -0.550 & 0.769 & & & & \\
\hline 3 & Adaptive Selling Behavior & -0.371 & 0.475 & 0.822 & & & \\
\hline 4 & Manager Aggressiveness & 0.321 & -0.270 & -0.319 & 0.712 & & \\
\hline 5 & Manager Decisiveness & -0.424 & 0.456 & 0.478 & -0.355 & 0.788 & \\
\hline \multirow[t]{4}{*}{6} & Salesperson Performance & -0.307 & 0.426 & -0.609 & -0.428 & 0.602 & 0.819 \\
\hline & Descriptive characteristics & & & & & & \\
\hline & Mean & 2.701 & 3.550 & 2.547 & 3.612 & 3.454 & 0.388 \\
\hline & Standard deviation & 0.691 & 0.772 & 0.581 & 0.754 & 0.660 & 0.711 \\
\hline
\end{tabular}

\subsection{Measurement}

All measures used in the study were assessed through a well-established 5 point Likert scale, ranging from strongly disagree (1) to strongly agree (5). To capture sales managers' aggressiveness, a widely used scale was adopted by Micevski et al. (2017), and it consists of 4 items. A sample item is "My manager could be described as "violent". Ethical sales leadership is another construct and designed by Brown et al. (2005) and measured on 6 items scale. A sample item is "My manager listens to what employees have to say". Emotional exhaustion is consists of 5 items and was adopted from the study of Lewin \& Sager (2009). A sample item is "I feel emotionally drained by the pressure my sales manager puts on me". Adaptive selling behavior is designed by Spiro \& Weitz (1990) and also consists of 5 items scale. A sample item is "I like to experiment with different sales approaches". Manager decisiveness is a moderating variable in the study and taken by the study of Mulki et al. (2012) containing 6 items scale. A sample item is "It is hard for my manager to come to a decision". Salesperson performance was also adopted from the literature by Itani et al.(2017) and Singh \& Das (2013) and consists of 5 items. A sample item is "The salesperson exceeds sales targets and objectives".

\section{Results}

\subsection{Evaluation of measurement model}

First, we accompanied a variety of initial tests which include normality, one-dimensionality, and outliers. No significant problem was found, thus indicating data validity. We then performed a descriptive, correlation (See Table 1) and confirmatory factor analysis to estimate the reliability and validity of the measurement model, which included all the multi-item scales. Composite reliability (CR), standardized factor loading (SFLs), and average variance extracted (AVE) values indicated good reliability and convergent validity.

Table 2

Standardized loading values and constructs' reliability

\begin{tabular}{|c|c|c|c|c|c|}
\hline & Construct & Indicator & CR & AVE & Cronbach's Alpha \\
\hline \multirow{4}{*}{ Sales Manager Aggressiveness } & SM-AGR1 & 0.740 & 0.727 & 0.507 & 0.724 \\
\hline & SM-AGR2 & 0.684 & & & \\
\hline & SM-AGR3 & 0.782 & & & \\
\hline & SM-AGR4 & 0.740 & & & \\
\hline \multirow{6}{*}{ Ethical Sales Leadership } & ELDR1 & - & 0.800 & 0.562 & 0.709 \\
\hline & ELDR2 & 0.805 & & & \\
\hline & ELDR3 & 0.750 & & & \\
\hline & ELDR4 & 0.685 & & & \\
\hline & ELDR5 & 0.719 & & & \\
\hline & ELDR6 & 0.712 & & & \\
\hline \multirow[t]{2}{*}{ Emotional } & EEX1 & 0.779 & 0.855 & 0.542 & 0.788 \\
\hline & EEX2 & 0.761 & & & \\
\hline \multirow{3}{*}{ Exhaustion } & EEX3 & 0.672 & & & \\
\hline & EEX4 & 0.784 & & & \\
\hline & EEX5 & 0.767 & & & \\
\hline \multirow[t]{4}{*}{ Adaptive Selling Behavior } & ASB1 & 0.757 & 0.805 & 0.511 & 0.801 \\
\hline & ASB2 & 0.729 & & & \\
\hline & ASB3 & 0.630 & & & \\
\hline & ASB4 & 0.731 & & & \\
\hline & MDS1 & 0.707 & 0.817 & 0.612 & 0.738 \\
\hline & MDS2 & 0.608 & & & \\
\hline Manager & MDS3 & 0.766 & & & \\
\hline \multirow{3}{*}{ Decisiveness } & MDS4 & 0.761 & & & \\
\hline & MDS5 & 0.546 & & & \\
\hline & MDS6 & 0.755 & & & \\
\hline \multirow{5}{*}{ Salesperson Performance } & SP1 & 0.544 & 0.785 & 0.532 & 0.811 \\
\hline & SP2 & 0.720 & & & \\
\hline & SP3 & 0.764 & & & \\
\hline & SP4 & 0.811 & & & \\
\hline & SP5 & 0.721 & & & \\
\hline
\end{tabular}


As shown in Table 2, the standardized factor loadings were all above 0.50 (Arbuckle, 2016), so we acknowledge each indicator's contribution to the established variable. Further, Cronbach's alpha $(\alpha)$ value is appropriate as the value was found to be above the 0.70 thresholds. Also, we achieved convergent validity, as the value of AVE and CR in the study meets the 0.50 threshold (Fornell \& Larcker, 1981; Hair et al., 2006). Then the fact that the average variance extracted from each latent variable must surpass the square correlation of each pair of constructs (Fornell \& Larcker, 1981). The measurement model showed satisfactory fit as reflected in the fit indices: chi-square $\left(X^{2}\right)=948.115$; standardized root mean square residual $(\mathrm{SRMR})=0.060$; normed fit index $(\mathrm{NFI})=0.77$. In last, the highest variance inflation factor (VIF) 1.865 is below the standard value of 3.3, defined by Kock (2015), indicating that there is no problem with multicollinearity.

\subsection{Effect size $\left(f^{2}\right)$}

We have made several PLS estimates, every time with the absence of a dominating construct in our proposed model only to identify the effect of an exogenous variable on the endogenous variable. It is proposed by Cohen (1988), that $\mathrm{f}^{2}$ values of $0.02,0.15$, and 0.35 are considered small, medium, and high respectively. Table 3 shows that sales managers' aggressiveness has medium effects on ethical sales leadership $\left(\mathrm{f}^{2}=0.079\right)$, while ethical sales leadership has large effects on emotional exhaustion $\left(f^{2}=0.433\right)$ and adaptive selling behavior $\left(f^{2}=0.291\right)$. Further, we also found large effects of adaptive selling behavior on salesperson performance $\left(\mathrm{f}^{2}=0.222\right)$. In last, sales manager aggressiveness has medium effect on salesperson performance $\left(\mathrm{f}^{2}=0.182\right)$.

Table 3

Effect size $\left(\mathrm{F}^{2}\right)$ statistics for the general model.

\begin{tabular}{|c|c|c|c|}
\hline & Hypotheses & $\mathbf{F}^{2}$ & Effects \\
\hline H1 & Manager Aggressiveness $\rightarrow$ Ethical Sales Leadership & 0.079 & Medium \\
\hline $\mathrm{H} 2$ & Ethical Sales Leadership $\rightarrow$ Emotional Exhaustion & 0.433 & Large \\
\hline $\mathrm{H} 3$ & Ethical Sales Leadership $\rightarrow$ Adaptive Selling Behavior & 0.291 & Large \\
\hline $\mathrm{H} 4$ & Emotional Exhaustion $\rightarrow$ Salesperson Performance & 0.091 & Medium \\
\hline H5 & Adaptive Selling Behavior $\rightarrow$ Salesperson Performance & 0.222 & Large \\
\hline H6 & Manager Aggressiveness $\rightarrow$ Salesperson Performance & 0.068 & Medium \\
\hline $\mathrm{H} 7$ & Manager Decisiveness $\rightarrow$ Salesperson Performance & 0.182 & Large \\
\hline
\end{tabular}

\subsection{The predictive power of the model $\left(Q^{2}\right)$}

We conducted a Stone and Geisser test using a blindfolding technique on SmartPLS to determine the predictive relevance of our structural model. If the $Q^{2}$ value of all dependent variables in the structural model is beyond zero $(>0)$ then the structural model has predictive relevance (Hair et al., 2016). As the $\mathrm{Q}^{2}$ values in Table 4 are all above zero, so here all dependent variables in the path model have predictive relevance.

\section{Table 4}

Blindfolding statistics for predictive relevance $\left(\mathrm{Q}^{2}\right)$ for the general model.

\begin{tabular}{|c|c|c|c|c|}
\hline S.No & Constructs & SSO & SSE & $\mathrm{Q}^{2}(=1-\mathrm{SSE} / \mathrm{SSO})$ \\
\hline 1 & Managers' Aggressiveness & 2398.44 & 2398.44 & 0.107 \\
\hline 2 & Ethical Sales Leadership & 2688.00 & 2514.28 & 0.064 \\
\hline 3 & Emotional Exhaustion & 1680.00 & 1605.55 & 0.044 \\
\hline 4 & Adaptive Selling Behavior & 1344.00 & 1212.33 & 0.098 \\
\hline 5 & Manager Decisiveness & 2115.00 & 1925.22 & 0.089 \\
\hline 6 & Salesperson Performance & 1344.00 & 1020.84 & 0.240 \\
\hline
\end{tabular}

\subsection{Coefficient of determination $\left(R^{2}\right)$}

The findings of the study show that our predictive constructs explain $60.7 \%\left(\mathrm{R}^{2}=0.607\right)$ of salesperson performance variance. The evaluation parameters here describe that values of $0.75,0.50$, and 0.25 are assumed large, medium, and weak correspondingly (Hair et al., 2016). Therefore, the described variance in the salesperson performance is observed as a moderator. In addition, sales managers' aggressiveness explains $17.1 \%\left(\mathrm{R}^{2}=0.171\right)$ of ethical sales leadership variance. Similarly, ethical sales leadership explain $30.2 \%\left(\mathrm{R}^{2}=0.302\right)$ variance of emotional exhaustion and $22.5 \%\left(\mathrm{R}^{2}=0.225\right)$ of adaptive selling behavior.

\subsection{Hypotheses test results}

We evaluated the research hypotheses using PLS-SEM. To assess the significance of relational hypotheses in our model, we conducted bootstrapping with 5000 resamples. In the structural model, a relationship is said to be significant if the $p$-value is less than 0.05 . Table 5 outlines the empirical results of the study. The results of the analysis using partial least square (PLS) reveal that sales managers' aggressiveness has a negative impact on ethical sales leadership $(\beta=-0.270, p=0.000)$. Hence, $\mathrm{H} 1$ is supported. For $\mathrm{H} 2$ and $\mathrm{H} 3$, we found a negative relationship between ethical sales leadership and emotional exhaustion 
$(\beta=-0.550, p=0.000)$, while ethical sales leadership has a positive impact on adaptive selling behavior $(\beta=0.475, p=0.001)$. Further, a negative and insignificant relationship was found between emotional exhaustion and salesperson performance $(\beta=$ $-0.077, p=0.169)$. Thus, H4 did not support the study. In addition, we found a positive impact of adaptive selling behavior on salesperson performance $(\beta=0.384, p=0.000)$. Besides, sales managers' aggressiveness has negatively associated with salesperson performance $(\beta=-0.201, p=0.000)$ Thus, H5 \& H6 supported the study.

\subsection{Mediating effects}

We explored the effect of sales managers' aggressiveness on salesperson performance through the serial mediating mechanism of ethical sales leadership, adaptive selling behavior, and emotional exhaustion (See Figure 1). We used the bootstrapping technique to test the indirect effect in the serial mediation model (Hayes, 2015). By using Partial Least Square (PLS), our results found the negative and insignificant indirect effect of sales manager aggressiveness on salesperson performance through the sequential mediation of ethical sales leadership and emotional exhaustion $(\beta=-0.011,[\mathrm{CI}:-0.006,0.031], p=$ 0.216). On the other hand, the results of our structural model show positive and significant serial mediation effects of ethical sales leadership and adaptive selling behavior between the relationship of sales managers' aggressiveness and salesperson performance $(\beta=0.049$, [CI: 0.093, 0.019], $p=0.015)$.

\subsection{Moderating effects}

The moderating role of sales manager decisiveness was also testified with the help of structural model results. To explore the moderating effect, we conducted both graphical and simple slope analyses. Table 5 and Figure 2 show that manager decisiveness is moderate between the relationship of emotional exhaustion and salesperson performance. We tested hypothesis $\mathrm{H} 7$ and found significant and positive moderation of manager decisiveness between emotional exhaustion and salesperson performance $(\beta=0.043$, [CI: $0.021,0.097], p=0.021)$, which means the effect of emotional exhaustion on salesperson performance reduces; when the salespeople perceive that their managers have the decisiveness. None of the control variables showed any significant relationship with the constructs in the model. Therefore, including moderation analysis, we ran the structural model without control variables.

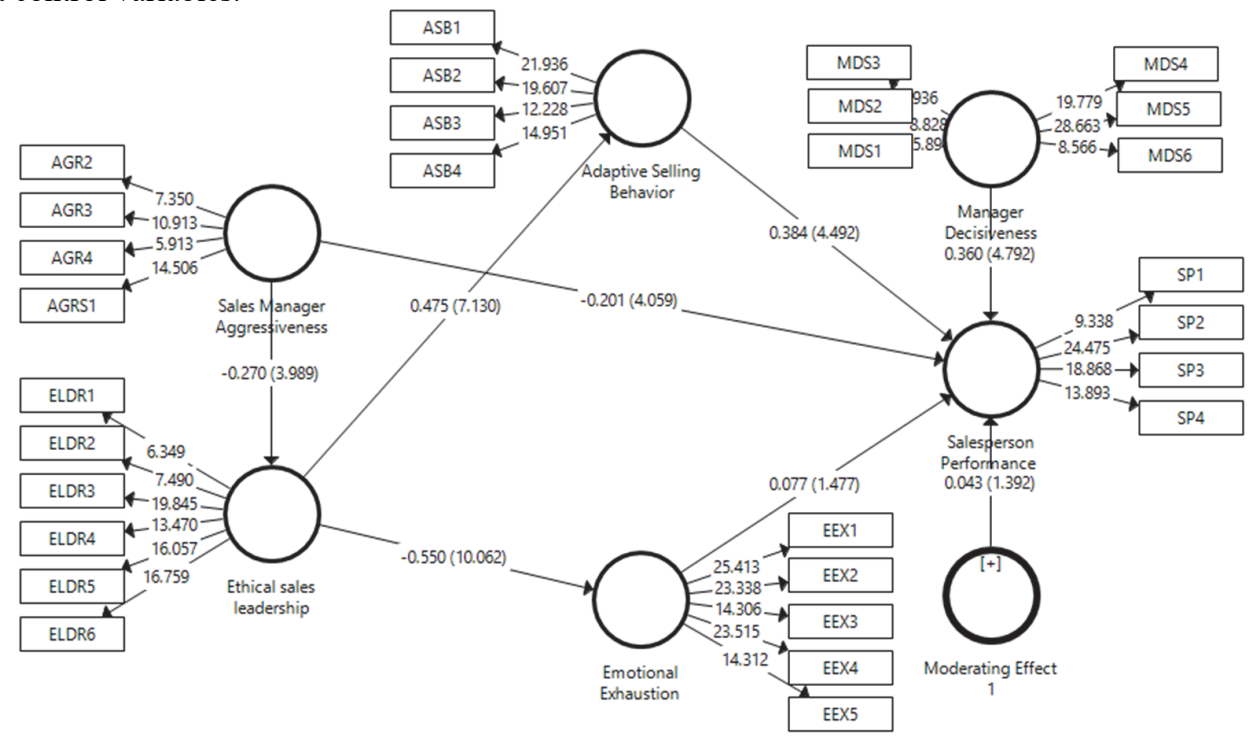

Fig. 2. Full structural model with beta $(\beta)$ and t values

Table 5

Significance of path coefficients

\begin{tabular}{|c|c|c|c|c|c|c|c|}
\hline \multirow{2}{*}{\multicolumn{2}{|c|}{ Hypotheses }} & \multirow{2}{*}{ Beta $(\beta)$} & \multirow{2}{*}{$p$-value } & \multirow{2}{*}{ SE } & \multicolumn{2}{|c|}{ Confidence Interval } & \multirow{2}{*}{ Decision } \\
\hline & & & & & $2.50 \%$ & $97.50 \%$ & \\
\hline $\mathbf{H}_{1}$ & $\mathrm{SM}-\mathrm{AGR} \rightarrow \mathrm{ESL}$ & -0.270 & 0.000 & 0.068 & -0.410 & -0.147 & Accepted \\
\hline $\mathbf{H}_{2}$ & $\rightarrow \mathrm{EE}$ & -0.550 & 0.000 & 0.053 & -0.651 & -0.451 & Accepted \\
\hline $\mathbf{H}_{3}$ & $\rightarrow \mathrm{ASB}$ & 0.475 & 0.001 & 0.065 & 0.340 & 0.606 & Accepted \\
\hline $\mathbf{H}_{4}$ & $\rightarrow \mathrm{SP}$ & -0.077 & 0.169 & 0.056 & -0.039 & 0.179 & Rejected \\
\hline $\mathbf{H}_{5}$ & $\rightarrow \mathrm{SP}$ & 0.384 & 0.000 & 0.084 & 0.232 & 0.572 & Accepted \\
\hline $\mathbf{H}_{6}$ & $\mathrm{SM}-\mathrm{AGR} \rightarrow \mathrm{SP}$ & -0.201 & 0.000 & 0.054 & -0.303 & -0.092 & Accepted \\
\hline $\mathbf{H}_{7}$ & $(\mathrm{MD} \times \mathrm{EE}) \rightarrow \mathrm{SP}$ & 0.043 & 0.021 & 0.030 & 0.021 & 0.097 & Accepted \\
\hline $\mathbf{H}_{8 \mathbf{a}}$ & $\mathrm{SM}-\mathrm{AGR} \rightarrow \mathrm{ESL} \rightarrow \mathrm{EE} \rightarrow \mathrm{SP}$ & -0.011 & 0.216 & 0.005 & -0.006 & 0.031 & Rejected \\
\hline $\mathbf{H}_{8 \mathrm{~b}}$ & $\mathrm{SM}-\mathrm{AGR} \rightarrow \mathrm{ESL} \rightarrow \mathrm{ASB} \rightarrow \mathrm{SP}$ & 0.049 & 0.015 & 0.020 & 0.093 & 0.019 & Accepted \\
\hline
\end{tabular}




\section{Discussion and implication}

Recent works on ethical leadership literature indicate that some managers practice behaviors that can be viewed as oppressive such as bullying (Valentine et al., 2015), social undermining (Eissa \& Wyland, 2018), and offensive behavior (S. Lee et al., 2018). Our study offers an important mechanism for controlling workplace aggression under ethical sales leadership that ultimately improves salesperson outcomes. However, the current study is amongst the few to explore the impact of sales managers' aggressiveness on ethical leadership in B2B sales literature. Previous research on sales managers' aggressiveness suggests that salespeople with rude supervisors are more likely to have a greater number of negative and traumatic experiences than those supervisors who do not personally encounter first-hand violent behavior (Micevski et al., 2017). Sales manager's aggressiveness is not only associated with disruption to the source of mistreatment but also with "compensation" damage to the company and others in the workplace. Consequently, unethical behavior can be strengthened by allowing actions that violate ethical norms by putting too much on managerial aggression and corporate performance. Therefore, our findings suggest that sales managers' aggressiveness is negatively associated with ethical sales leadership. Based on the above argument we evidence that our results support this prediction.

Besides, previous studies have confirmed that workplace aggression is related to employees' negative or undermined frame of mind and behaviors (Geddes \& Baron, 1997; Micevski et al., 2017). The current study shows the development and validation of the framework from a stress perspective that describes how and when sales managers' aggressiveness is associated with the withdrawal of work by the salespeople. We further found that sales managers' aggressiveness is positively associated with EE and negatively associated with salesperson performance, thus the findings of our research are consistent with the study of Chi \& Liang (2013). The salesperson's behavior can improve customer relationships by meeting customer expectations and making appropriate changes. As a result, numerous researchers have found a favorable association between adaptive selling and employee performance in a variety of selling contexts. In particular, our findings are parallel with the study of Limbu et al. (2016) who found a positive connection between adaptive selling behavior and other positive sales outcomes. This study also investigates how managers' decisiveness moderates the effect of emotional exhaustion on salesperson performance. Decisive managers are perceived to be straightforward on their objectives and a course of decisions (Barrick \& Zimmerman, 2005). Although, our findings show that managers' decisiveness has positive moderation among the relationship of emotional exhaustion and salesperson performance. In last, the purpose of this study is to investigate the impact of sales managers' aggressiveness on ethical sales leadership and salesperson performance, taking into account the sequential mediation of emotional exhaustion and adaptive selling behavior.

\subsection{Theoretical contributions}

Our research contributes to the sales management framework by expanding past studies in the following aspects. The first contribution of this study is to explore the effect of sales managers' aggressiveness on ethical sales leadership in B2B setting. However, limited empirical studies have conducted the perspective of ethical leadership in the B2B sales context. We argue that sales managers' aggressiveness is a possible predictor of ethical sales leadership which has not been previously discussed in sales literature. We also contribute to the leadership management literature by investigating the relationship between ethical sales leadership and adaptive selling behavior which is difficult to find in the prior work. The study adds to the literature by examining the sequential mediation of emotional exhaustion and adaptive selling behavior between the relationship of sales managers' aggressiveness and salesperson performance. Finally, we contribute to the trust and management literature by employing manager decisiveness as a moderating construct in our study.

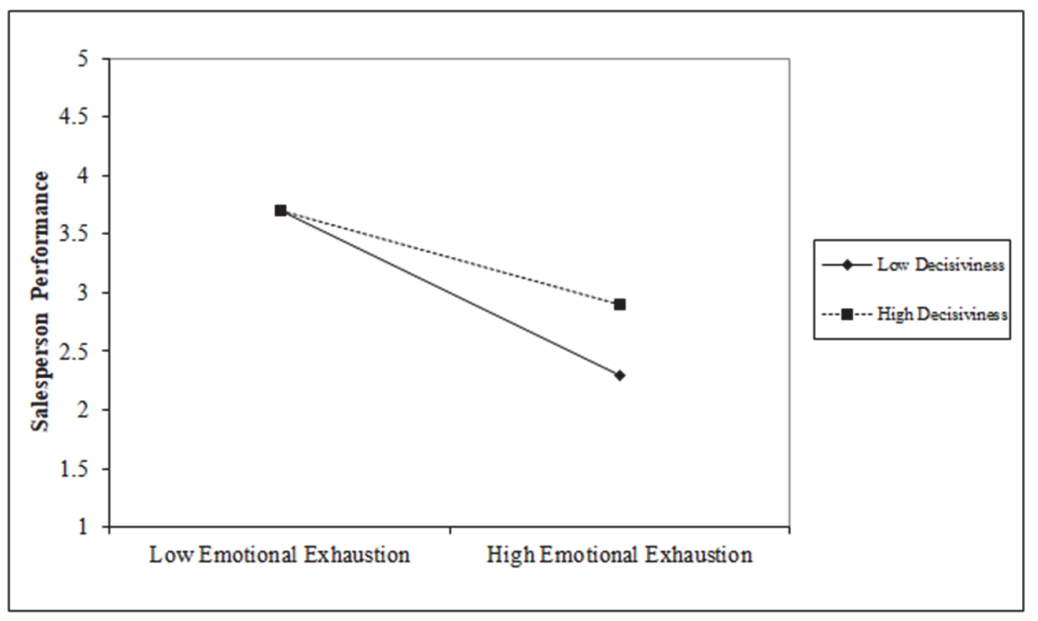

Fig. 3. Simple slope analysis 


\subsection{Practical implications}

The current study provides marketers with some valuable insights into sales and leadership management. In general, it wasn't only the quality of decision-making by sales managers that is crucial, but how those decisions are implemented in communicating with their salespeople. In this context, particular advice to sales managers is to rethink their aggressive strategy both as primarily good or evil and also as mutually contradictory. Our results suggest that the lowest level of EE and the highest level of ethical sales leadership will be achieved with a low level of aggressive behavior. Unethical behavior has been considered an important concern for many organizations. The findings of the study propose that sales managers' aggressiveness can increase the level of violence and prevent salespeople from trying to stand up and take action when social and corporate ethical standards are challenged, which ultimately affect their performance outcomes. Therefore, sales managers' aggressiveness should be reported and either advised to stop such actions or taken away from the company.

\subsection{Limitations and future research}

This study provides a number of major contributions to the body of knowledge. However, it also has some limitations. First, our study is cross-sectional and it is the main form of inquiry in salespersons' studies (Lewin \& Sager, 2007). Future studies could be longitudinal in order to enable researchers to analyze the salesperson's emotional exhaustion and performance, and collect the data at different periods in time that can boost the direct cause and effect of the studied constructs. The explained variance for ethical sales leadership is $17.1 \%$ which is significantly above the minimum ordinary value defined by Falk $\&$ B. Miller (1992). This suggests that several other endogenous variables should be applied to improve the predictive strength of ethical sales leadership and salesperson performance. In the future, scholars may also add sales managers' personality traits as an exogenous variable which could be a strong predictor of ethical leadership behavior. Further, scholars might expand the model by investigating other leadership styles in the B2B sales context (i.e., transformational leadership and servant leadership). Another limitation is the use of a single geographical location in a Pakistani setting as a sample frame. Consequently, based on cultural perceptions, the data can also be derived from various geographic regions for the accuracy and generalization of the results.

\section{Acknowledgement}

The author acknowledges that there is no competing interest. All the authors contributed equally to conduct this research. This article followed all ethical standards for carrying out the research. This research received no specific grant from any funding agency in the public, commercial or not-for-profit sectors. The view and opinions expressed in this paper are those of the authors and do not necessarily reflect the official policy or position of any affiliated agency of the authors.

\section{References}

Aquino, K., Galperin, B. L., \& Bennett, R. J. (2004). Social status and aggressiveness as moderators of the relationship between interactional justice and workplace deviance. In Journal of Applied Social Psychology (Vol. 34, Issue 5, pp. 1001-1029). Blackwell Publishing Ltd. https://doi.org/10.1111/j.1559-1816.2004.tb02581.x

Aquino, K., \& Thau, S. (2009). Workplace victimization: Aggression from the target's perspective. In Annual Review of Psychology (Vol. 60, pp. 717-741). https://doi.org/10.1146/annurev.psych.60.110707.163703

Arbuckle, J. L. (2016). IBM SPSS Amos 21: User's Guide.

Barrick, M. R., \& Zimmerman, R. D. (2005). Reducing voluntary, avoidable turnover through selection. Journal of Applied Psychology, 90(1), 159-166. https://doi.org/10.1037/0021-9010.90.1.159

Brown, M. E., \& Mitchell, M. S. (2010). Ethical and Unethical Leadership: Exploring New Avenues for Future Research. Business Ethics Quarterly, 20(4), 583-616. https://doi.org/10.5840/beq201020439

Brown, M. E., \& Treviño, L. K. (2006). Socialized charismatic leadership, values congruence, and deviance in work groups. Journal of Applied Psychology, 91(4), 954-962. https://doi.org/10.1037/0021-9010.91.4.954

Brown, M. E., Treviño, L. K., \& Harrison, D. A. (2005). Ethical leadership: A social learning perspective for construct development and testing. Organizational Behavior and Human Decision Processes, 97(2), 117-134. https://doi.org/10.1016/j.obhdp.2005.03.002

Busch, P., \& Bush, R. F. (1978). Women Contrasted to Men in the Industrial Salesforce: Job Satisfaction, Values, Role Clarity, Performance, and Propensity to Leave. Journal of Marketing Research, 15(3), 438. https://doi.org/10.2307/3150592

Chi, S. C. S., \& Liang, S. G. (2013). When do subordinates' emotion-regulation strategies matter? Abusive supervision, subordinates' emotional exhaustion, and work withdrawal. Leadership Quarterly, 24(1), 125-137. https://doi.org/10.1016/j.leaqua.2012.08.006

Cohen, J. (1988). Statistical power analysis for the behavioral sciences (2nd ed.). L. Erlbaum Associates.

Dixon, A. L., \& Schertzer, S. M. B. (2005). Bouncing back: How salesperson optimism and self-efficacy influence attributions and behaviors following failure? Journal of Personal Selling and Sales Management, 25(4), 361-369. https://doi.org/10.1080/08853134.2005.10749070

Do, D. T., Nguyen, T. H., Nguyen, T. H. N., Ha, H. H., \& Le, T. T. (2020). The influence of leadership style on accountants' commitment with enterprise: An empirical study on Vietnamese FDI Firms. Journal of Asian Finance, Economics and Business, 7(3), 235-243. https://doi.org/10.13106/jafeb.2020.vol7.no3.235 
Eissa, G., \& Wyland, R. (2018). Work-Family Conflict and Hindrance Stress as Antecedents of Social Undermining: Does Ethical Leadership Matter? Applied Psychology, 67(4), 645-654. https://doi.org/10.1111/apps.12149

Falk, R., \& B. Miller, N. (1992). A Primer for Soft Modeling. University of Akron Press, USA. https://www.researchgate.net/publication/232590534_A_Primer_for_Soft_Modeling

Fornell, C., \& Larcker, D. F. (1981). Evaluating Structural Equation Models with Unobservable Variables and Measurement Error. Journal of Marketing Research, 18(1), 39. https://doi.org/10.2307/3151312

Geddes, D., \& Baron, R. A. (1997). Workplace Aggression as a Consequence of Negative Performance Feedback. Management Communication Quarterly, 10(4), 433-454. https://doi.org/10.1177/0893318997104002

Germeijs, V., Verschueren, K., \& Soenens, B. (2006). Indecisiveness and high school students' career decision-making process: Longitudinal associations and the mediational role of anxiety. Journal of Counseling Psychology, 53(4), 397410. https://doi.org/10.1037/0022-0167.53.4.397

Gino, F., Schweitzer, M. E., Mead, N. L., \& Ariely, D. (2011). Unable to resist temptation: How self-control depletion promotes unethical behavior. Organizational Behavior and Human Decision Processes, 115(2), 191-203. https://doi.org/10.1016/j.obhdp.2011.03.001

Hair, J. F., Black, W. C., Babin, B. J., \& Anderson, R. E. (2006). Multivariate Data Analysis. Prentice-Hall, Inc.

Hair, J. F., M. Hult, G. T., Ringle, C., \& Sarstedt, M. (2016). A Primer on Partial Least Squares Structural Equation Modeling (PLS-SEM). SAGE Publication Inc. https://us.sagepub.com/en-us/nam/a-primer-on-partial-least-squares-structuralequation-modeling-pls-sem/book244583

Halbesleben, J. R. B. (2006). Sources of social support and burnout: A meta-analytic test of the conservation of resources model. Journal of Applied Psychology, 91(5), 1134-1145. https://doi.org/10.1037/0021-9010.91.5.1134

Halbesleben, J. R. B., \& Bowler, W. M. (2007). Emotional exhaustion and job performance: The mediating role of motivation. Journal of Applied Psychology, 92(1), 93-106. https://doi.org/10.1037/0021-9010.92.1.93

Hayes, A. F. (2015). An Index and Test of Linear Moderated Mediation. Multivariate Behavioral Research, 50(1). https://doi.org/10.1080/00273171.2014.962683

Hobfoll. (1989). Conservation of Resources: A New Attempt at Conceptualizing Stress. American Psychologist, 44(3), 513524. https://doi.org/10.1037/0003-066X.44.3.513

Hobfoll, S. E. (2001). The influence of culture, community, and the nested-self in the stress process: Advancing conservation of resources theory. Applied Psychology, 50(3), 337-421. https://doi.org/10.1111/1464-0597.00062

Ingram, T. N., LaForge, R. W., \& Schwepker, C. H. (2013). Salesperson ethical decision making: The impact of sales leadership and sales management control strategy. Journal of Personal Selling and Sales Management, 27(4), 301-315. https://doi.org/10.2753/PSS0885-3134270402

Itani, O. S., Agnihotri, R., \& Dingus, R. (2017). Social media use in B2b sales and its impact on competitive intelligence collection and adaptive selling: Examining the role of learning orientation as an enabler. Industrial Marketing Management, 66, 64-79. https://doi.org/10.1016/j.indmarman.2017.06.012

Jaramillo, F., Locander, W. B., Spector, P. E., \& Harris, E. G. (2007). Getting the job done: The moderating role of initiative on the relationship between intrinsic motivation and adaptive selling. Journal of Personal Selling and Sales Management, 27(1), 59-74. https://doi.org/10.2753/PSS0885-3134270104

Jaramillo, F., Mulki, J., \& Boles, J. (2011). Workplace stressors, job attitude, and job behaviors: Is interpersonal conflict the missing link? Journal of Personal Selling and Sales Management, 31(3), 339-356. https://doi.org/10.2753/PSS08853134310310

Kalshoven, K., Den Hartog, D. N., \& De Hoogh, A. H. B. (2011). Ethical leadership at work questionnaire (ELW): Development and validation of a multidimensional measure. Leadership Quarterly, 22(1), 51-69. https://doi.org/10.1016/j.leaqua.2010.12.007

Kock, N. (2015). Common method bias in PLS-SEM: A full collinearity assessment approach. International Journal of ECollaboration, 11(4), 1-10. https://doi.org/10.4018/ijec.2015100101

Lam, C. K., Walter, F., \& Huang, X. (2017). Supervisors' emotional exhaustion and abusive supervision: The moderating roles of perceived subordinate performance and supervisor self-monitoring. Journal of Organizational Behavior, 38(8), 1151-1166. https://doi.org/10.1002/job.2193

Lee, N., \& Cadogan, J. W. (2009). Sales force social exchange in problem resolution situations. Industrial Marketing Management, 38(3), 355-372. https://doi.org/10.1016/j.indmarman.2008.02.002

Lee, S., Kim, S. L., \& Yun, S. (2018). A moderated mediation model of the relationship between abusive supervision and knowledge sharing. Leadership Quarterly, 29(3), 403-413. https://doi.org/10.1016/j.leaqua.2017.09.001

Lewin, J. E., \& Sager, J. K. (2007). A process model of burnout among salespeople: Some new thoughts. Journal of Business Research, 60(12), 1216-1224. https://doi.org/10.1016/j.jbusres.2007.04.009

Lewin, J. E., \& Sager, J. K. (2008). Salesperson burnout: A test of the coping-mediational model of social support. Journal of Personal Selling and Sales Management, 28(3), 233-246. https://doi.org/10.2753/PSS0885-3134280302

Lewin, J. E., \& Sager, J. K. (2009). An investigation of the influence of coping resources in salespersons' emotional exhaustion. Industrial Marketing Management, 38(7), 798-805. https://doi.org/10.1016/j.indmarman.2008.02.013

Li, N., \& Murphy, W. H. (2012). A Three-Country Study of Unethical Sales Behaviors. Journal of Business Ethics, 111(2), 219-235. https://doi.org/10.1007/s10551-012-1203-z

Limbu, Y. B., Jayachandran, C., Babin, B. J., \& Peterson, R. T. (2016). Empathy, nonverbal immediacy, and salesperson performance: the mediating role of adaptive selling behavior. Journal of Business and Industrial Marketing, 31(5), 654- 
667. https://doi.org/10.1108/JBIM-03-2015-0048

Micevski, M., Kadic-Maglajlic, S., Banerjee, S., Cadogan, J., \& Lee, N. (2017). Is it better to be both nice and nasty? Investigating the co-occurrence of sales manager aggressiveness and caring. Journal of Business Research, 80, $266-276$. https://doi.org/10.1016/j.jbusres.2017.05.018

Mulki, J. P., Jaramillo, F., \& Locander, W. B. (2006). Emotional exhaustion and organizational deviance: Can the right job and a leader's style make a difference? Journal of Business Research, 59(12), $1222-1230$. https://doi.org/10.1016/j.jbusres.2006.09.001

Mulki, J. P., Jaramillo, F., Malhotra, S., \& Locander, W. B. (2012). Reluctant employees and felt stress: The moderating impact of manager decisiveness. Journal of Business Research, 65(1), 77-83. https://doi.org/10.1016/j.jbusres.2011.01.019

Nguyen, H. M., Nguyen, C., Ngo, T. T., \& Nguyen, L. V. (2019). The effects of job crafting on work engagement and work performance: A study of Vietnamese commercial banks. Journal of Asian Finance, Economics and Business, 6(2), 189201. https://doi.org/10.13106/jafeb.2019.vol6.no2.189

Schwepker, C. H. (2015). Influencing the salesforce through perceived ethical leadership: The role of salesforce socialization and persona-organization fit on salesperson ethics and performance. Journal of Personal Selling and Sales Management, 35(4), 292-313. https://doi.org/10.1080/08853134.2015.1106769

Schwepker, C. H. (2019). Using Ethical Leadership to Improve Business-To-Business Salesperson Performance: The Mediating Roles of Trust in Manager and Ethical Ambiguity. Journal of Business-to-Business Marketing, 26(2), $141-158$. https://doi.org/10.1080/1051712X.2019.1603358

Schwepker, C. H., \& Ingram, T. N. (2016). Ethical leadership in the salesforce: effects on salesperson customer orientation, commitment to customer value and job stress. Journal of Business and Industrial Marketing, 31(7), 914-927. https://doi.org/10.1108/JBIM-07-2015-0136

Sims, R. R., \& Brinkmann, J. (2002). Leaders as moral role models: The case of John Gutfreund at Salomon Brothers. Journal of Business Ethics, 35(4), 327-339. https://doi.org/10.1023/A:1013826126058

Singh, R., \& Das, G. (2013). The impact of job satisfaction, adaptive selling behaviors and customer orientation on salesperson's performance: Exploring the moderating role of selling experience. Journal of Business and Industrial Marketing, 28(7), 554-564. https://doi.org/10.1108/JBIM-04-2011-0121

Spiro, R. L., \& Weitz, B. A. (1990). Adaptive Selling: Conceptualization, Measurement, and Nomological Validity. Journal of Marketing Research, 27(1), 61. https://doi.org/10.2307/3172551

Sprung, J. M., Sliter, M. T., \& Jex, S. M. (2012). Spirituality as a moderator of the relationship between workplace aggression and employee outcomes. Personality and Individual Differences, 53(7), 930-934. https://doi.org/10.1016/j.paid.2012.06.011

Valentine, S., Fleischman, G., \& Godkin, L. (2015). Rogues in the ranks of selling organizations: Using corporate ethics to manage workplace bullying and job satisfaction. Journal of Personal Selling and Sales Management, 35(2), $143-163$. https://doi.org/10.1080/08853134.2015.1010542

Walumbwa, F. O., Mayer, D. M., Wang, P., Wang, H., Workman, K., \& Christensen, A. L. (2011). Linking ethical leadership to employee performance: The roles of leader-member exchange, self-efficacy, and organizational identification. Organizational Behavior and Human Decision Processes, 115(2), 204-213. https://doi.org/10.1016/j.obhdp.2010.11.002

Wang, Q., Bowling, N. A., \& Eschleman, K. J. (2010). A meta-analytic examination of work and general locus of control. Journal of Applied Psychology, 95(4), 761-768. https://doi.org/10.1037/a0017707

Weitz, B. A., Sujan, H., \& Sujan, M. (1986). Knowledge, Motivation, and Adaptive Behavior: A Framework for Improving Selling Effectiveness. Journal of Marketing, 50(4), 174. https://doi.org/10.2307/1251294

Wu, Y. C. (2017). Mechanisms Linking Ethical Leadership to Ethical Sales Behavior. Psychological Reports, 120(3), 537560. https://doi.org/10.1177/0033294117693594

Yoon, D. W., Kim, B. Y., \& Oh, S. H. (2020). Core self-evaluation and sales performance of female salespeople in face-toface channel. Journal of Asian Finance, Economics and Business, 7(5), $205-216$. https://doi.org/10.13106/JAFEB.2020.VOL7.NO5.205

Zheng, D., Witt, L. A., Waite, E., David, E. M., van Driel, M., McDonald, D. P., Callison, K. R., \& Crepeau, L. J. (2015). Effects of ethical leadership on emotional exhaustion in high moral intensity situations. Leadership Quarterly, 26(5), 732748. https://doi.org/10.1016/j.leaqua.2015.01.006

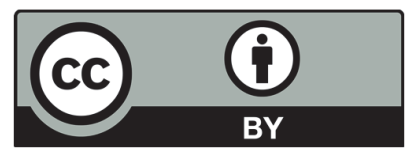

(C) 2021 by the authors; licensee Growing Science, Canada. This is an open access article distributed under the terms and conditions of the Creative Commons Attribution (CC-BY) license (http://creativecommons.org/licenses/by/4.0/). 